Please do not remove this page

RMIT

UNIVERSITY

\title{
Air-conditioning and antibiotics: Demand management insights from problematic health and household cooling practices
}

Nicholls, Larissa; Strengers, Yolande

https://researchrepository.rmit.edu.au/esploro/outputs/9921859993601341/filesAndLinks?institution=61RMIT_INST\&index=null

Nicholls, L., \& Strengers, Y. (2014). Air-conditioning and antibiotics: Demand management insights from problematic health and household cooling practices. Energy Policy, 67, 673-681.

https://doi.org/10.1016/j.enpol.2013.11.076

Document Version: Accepted Manuscript

Published Version: https://doi.org/10.1016/j.enpol.2013.11.076

Repository homepage: https://researchrepository.rmit.edu.au

(c) 2013 Elsevier Ltd. All rights reserved.

Downloaded On 2023/04/27 00:28:49 +1000 
Thank you for downloading this document from the RMIT Research Repository.

The RMIT Research Repository is an open access database showcasing the research outputs of RMIT University researchers.

RMIT Research Repository: http://researchbank.rmit.edu.au/

\section{Citation:}

Nicholls, L and Strengers, Y 2014, 'Air-conditioning and antibiotics: Demand management insights from problematic health and household cooling practices', Energy Policy, vol. 67, pp. 673-681.

See this record in the RMIT Research Repository at:

https://researchbank.rmit.edu.au/view/rmit:24423

Version: Accepted Manuscript

Copyright Statement: (c) 2013 Elsevier Ltd. All rights reserved.

Link to Published Version:

http://dx.doi.org/10.1016/j.enpol.2013.11.076 
Title: Air-conditioning and antibiotics: Demand management insights from problematic health and household cooling practices

\section{Authors Names:}

Dr Larissa Nicholls ${ }^{a}$

larissa.nicholls@rmit.edu.au

Dr Yolande Strengers ${ }^{a}$

yolande.strengers@rmit.edu.au

\section{Author Affiliations:}

${ }^{\mathrm{a} C e n t r e ~ f o r ~ U r b a n ~ R e s e a r c h, ~ R M I T ~ U n i v e r s i t y, ~ G P O ~ B o x ~ 2476, ~ M e l b o u r n e, ~ V i c t o r i a ~ 3001, ~}$ Australia

\section{Corresponding author:}

Dr Larissa Nicholls

larissa.nicholls@rmit.edu.au

RMIT University, GPO Box 2476, Melbourne, Victoria 3001, Australia

Phone +61399259012 


\begin{abstract}
:
Air-conditioners and antibiotics are two technologies that have both been traditionally framed around individual health and comfort needs, despite aspects of their use contributing to social health problems. The imprudent use of antibiotics is threatening the capacity of the healthcare system internationally. Similarly, in Australia the increasing reliance on airconditioning to maintain thermal comfort is contributing to rising peak demand and electricity prices, and is placing an inequitable health and financial burden on vulnerable heat-stressed households. This paper analyses policy responses to these problems through the lens of social practice theory. In the health sector, campaigns are attempting to emphasise the social health implications of antibiotic use. In considering this approach in relation to the problem of air-conditioned cooling and how to change the ways in which people keep cool during peak times, our analysis draws on interviews with 80 Australian households. We find that the problem of peak electricity demand may be reduced through attention to the social health implications of air-conditioned cooling on very hot days. We conclude that social practice theory offers a fruitful analytical route for identifying new avenues for research and informing policy responses to emerging health and environmental problems.
\end{abstract}

Keywords: peak demand; electricity; demand management; social practices 


\section{Introduction}

While not immediately obvious, the synergies between air-conditioning and antibiotics are striking. Both are individually administered and consumed, and both exacerbate global health and environmental problems such as antibiotic resistance, climate change and peak electricity demand. In particular, the imprudent of antibiotics to treat minor infections, such as the common cold, is contributing to the emergence of antibiotic resistant microbes which can cause largely untreatable serious infections. Increasing antibiotic resistance is making societies vulnerable to outbreaks of infection and leading to a dramatic decline in healthcare capabilities. This is similar to the ways in which the increasing use of air-conditioning on hot summer days increases the complexity and costs of meeting peak electricity demand (Faruqui and Palmer, 2011). Peak electricity demand is creating serious health concerns, particularly for low-income households, where many of those most vulnerable to heat stress reside (Bi et al., 2011; Klinenberg, 2002). Some of those most in need of air-conditioning to maintain health are struggling with rapidly increasing electricity costs and either cannot afford to install an air-conditioner, or opt not to use an existing air-conditioner or fan during extreme heat events due to their concern about the impact on their electricity bill (Farbotko and Waitt, 2011; Sheridan, 2007). Furthermore, low-income homes are often affected by poor urban design and insufficient thermal insulation and ventilation which can exacerbate high temperatures and heat-related health impacts in summer (Bonnefoy et al., 2004; Morris and Simmonds, 2000).

The different policy responses to the problems of antibiotics and air-conditioning provide important insights for energy policy makers. The issue of peak electricity demand has prompted a suite of demand management initiatives, regulations and policies such as timebased or critical peak pricing, which penalise or reward households for increasing or reducing their peak consumption, particularly air-conditioning usage (Faruqui and Palmer, 
2011). These programs emphasise the personal benefits and savings householders receive for reducing peak demand (and in some cases environmental benefits). Policy responses to antibiotic use have also emphasised personal restraint and benefits, but recently greater emphasis is being placed on the wider social and health implications and the need for reduced or 'prudent' antibiotic use to protect the health of others and the healthcare system in the future (Davies, 2013). While the success or otherwise of this antibiotic strategy is not yet known, the social health implications of increasing antibiotic usage represents an important parallel with the energy sector, where increasing air-conditioning usage has important health and equity implications that are not being widely discussed or promoted. In this paper we explore the possibility of repositioning the problem of peak demand and airconditioning use as a public health issue, rather than an issue of personal choice, and individual benefits. In particular, we speculate on how emphasising the social health implications of increased air-conditioning usage on hot summer days in demand management programs might change what makes sense for householders to do in order to stay cool during these times.

We approach this analysis from a social practice theoretical understanding of socio-technical change. Using Shove et al.'s (2012) summation of a practice 'entity', we position antibiotics and air-conditioners as technologies or materials of the social practices of treating minor infections (such as the common cold) and keeping cool on hot days, where they sit alongside the elements of meanings and competencies which together co-constitute 'normal' ways of staying healthy and cool. Following Schatzki (2002) and Shove et al. (2012), we are also interested in practice-as-performance, and the ways in which 'new' and 'old' versions of these practices are performed. Practices of treating minor infections aim to reduce the symptoms of an ailment and facilitate rapid recovery. They are usually performed by health professionals and patients in concert. Practices of keeping cool on hot days in order to 
maintain bodily coolth, comfort and health are widely performed, but we focus here on the performance of these practices in households, by householders.

In undertaking this analysis, we do not wish to suggest that some policy interventions to reduce antibiotic or air-conditioning usage are framed from or informed by a social practices perspective while others are not. Rather, our aim is to explore the possibility that some policy responses are more likely to achieve practice change than others, by virtue of where and on who (or what) they focus their attention. The value of analysing policy responses in this way has been previously demonstrated by a growing number of scholars who have studied the impact of dominant and innovative policy responses on everyday practices to inform practiceoriented policymaking (Evans et al., 2012, Hargreaves, 2011; Shove and Walker, 2010, Strengers, 2012). Our exploration is informed by qualitative research with 80 households from Australia, with whom we discussed the issue of peak electricity demand and current cooling practices.

It is important to clarify from the outset that we assume that access to affordable electricity to run air-conditioning or fans is essential to achieve healthy, equitable outcomes for a portion of vulnerable, elderly or chronically ill householders. While we do not preference airconditioning as a solution to heat stress we do acknowledge that in some cases it may be necessary due to the poor thermal performance of many residential buildings, urban design problems and additional issues which can affect the capacity for householders to participate in other practices of keeping cool (Bonnefoy et al., 2004; Morris and Simmonds, 2000). Our focus is therefore on how policy makers and energy demand managers can reduce the use of air-conditioned cooling by the more able majority to alleviate peak electricity demand and air-conditioning reliance for the benefit of the vulnerable, the electricity system, and the environment. 
The paper begins by further outlining our theoretical framework, drawing synergies between air-conditioning and antibiotics and the practices they are implicated in. We then turn to a distinctive emerging policy response in the healthcare sector, which we analyse as an attempt to change doctors' and patients' practices of using antibiotics to treat minor ailments. Taking cues from this example, we analyse our empirical data with Australian households to consider how practices of keeping cool are currently constituted and performed, and how policy makers and demand managers could encourage these practices to shift or change, particularly during peak times. We conclude by considering the research and policy opportunities from our analysis and the implications for energy demand management programs.

\section{Antibiotics and air-conditioning as 'materials' of practice}

Ancient human civilisations used techniques such as hanging moistened reeds to humidify and cool air as it passed through the home. In a similar vein, antibiotic substances produced by organisms to achieve competitive advantage in their environment have long been used by humans as part of traditional medicine practices. Scientific advances in the first half of the $20^{\text {th }}$ Century included the identification and production of penicillin for use as an antibiotic medicine to treat infections and the application of refrigeration chemistry to develop mechanical air-conditioning units for home use. This harnessing of human scientific understanding to commodify natural processes in order to achieve a practical outcome constitutes both modern air-conditioning and commercial antibiotics as 'technologies'. Through the second half of the $20^{\text {th }}$ Century these two technologies have revolutionised the respective practices of keeping cool and treatment of infections. The development of each of these technologies is typically viewed as an 'advance' in human civilisation whereby higher 
levels of health and/or sense of wellbeing are achieved (Spellberg et al., 2008; Trippett, 1979).

Following Shove et al. (2012) we treat the technologies of air-conditioning (primarily refrigerated cooling) and antibiotics as dominant 'materials' of their respective practices. As we outlined in the introduction, materials are an integral element of the social practice entity, sitting alongside competences (or skills) and meanings (or understandings), which relate to social, cultural or symbolic phenomena (Shove et al., 2012). Importantly, these elements are interrelated and overlapping; hence meanings can be held about competencies or materials, such as meanings about air-conditioning and electricity, and materials and competencies can similarly inform meanings. Taken together, the use of the air-conditioner to keep cool relies on competences about how to use an air-conditioner and meanings of air-conditioned cooling as the best and most appropriate method for very hot days. While 'normal' ways of performing social practices are dynamic and change over time (Shove et al., 2012), in many countries antibiotics and air-conditioning are now both commonly considered necessary and superior materials of their respective suites of practice (Mangione-Smith et al., 2004; Shove, 2003).

As a material of practice, air-conditioning and its associated thermal comfort standards (ASHRAE, 2004) has played a critical role in changing householders' expectations of comfort, personal presentation and hygiene (Shove, 2003). For example, workplaces are airconditioned to temperatures that accommodate the wearing of suits in summer. Sweatingthe human body's in-built physiological cooling process-is now commonly avoided via the use of chemical antiperspirants (Aaland, 1978; Auliciems, 1972; Gram-Hanssen, 2007). In Australia, the shifting status of air-conditioning from a 'luxury item' to a 'necessity' over the past two to three decades is evidenced by high penetration rates in Australian homes (over $73 \%$ of homes (ABS, 2011)) and energy saving programs that suggest reducing the number 
rooms being cooled or increasing the thermostat setting instead of turning the air-conditioner off or using other means to stay cool, (for example, Energy Assistance Guide (DoTI, 2011)). Increased electricity costs and the risk of reduced electricity reliability as a result of the high use of air-conditioning in Australia (ESAA, 2012) and other countries has serious implications for vulnerable householders who may need electricity (and cooling) to maintain their health during heat waves (WHO, 2009).

There are a number of important parallels between the changing role of air-conditioning in cooling practices and the proliferation of antibiotic use in the practices of treating minor ailments. Antibiotics have long been known to be unnecessary and ineffective as treatments for minor ailments such as the common cold (Stott, 1979; Whitfield and Hughes, 1981). The use of antibiotics for this type of minor ailment has continued and is often considered a normal, necessary and expected aspect of treatment (Davey et al., 1996; Mainous et al., 1998; Mangione-Smith et al., 2004). Doctors report prescribing unwarranted antibiotics in response to anticipated or expressed patient expectations (Butler et al., 1998; Cockburn and Pit, 1997). As such, the use of antibiotics has overshadowed other competences and materials of treating minor ailments, such as recovering from a cold with hot lemon drinks and rest in bed.

As with air-conditioning, the popularity of antibiotic use has led to problems with the availability and effectiveness of this material. In addition to human and veterinary healthcare, antibiotics have made their way into a myriad of other practices. They are used in vast quantities to increase growth rates and reduce production costs of fish and food animals. Many cleaning products now contain antibiotics regardless of evidence that their inclusion is not necessary or healthier (SGV, 2013). Widespread use of antibiotics has caused the emergence of antibiotic resistance $(\mathrm{DoH}, 1999)$ as bacteria mutate or acquire new genes that enable them to overcome the inhibitory effect of antibiotics. In the absence of the discovery 
of new antibiotics, previously treatable diseases such as pneumonia, tuberculosis and wound infections are causing increasing morbidity, mortality and strain on the healthcare system. Surgery is becoming riskier as hospitals struggle to control the transmission of antibiotic resistant infections in hospitals. It has been estimated that 25,000 people die each year in the European Union from antibiotic-resistant bacterial infections (ECDC/EMA, 2009).

Despite the potential for cumulative over-use of antibiotics to have wide-ranging health and environmental implications, antibiotic use has traditionally been framed as an issue of individual choice in personal health and/or comfort. Similarly, household air-conditioner use is commonly framed as an issue of individual comfort preferences and affordability (Strengers and Maller, 2011). However, more recently health agencies and policy makers have sought to emphasise and promote the social health implications of antibiotic use, and suggest other methods of treating minor ailments. We acknowledge that this approach could be considered consistent with the traditional 'attitudes, behaviour, choice' (ABC) model of behaviour change which is critiqued by social practice researchers as placing individuals at the forefront of responsibility for social change without acknowledging the role of institutions, and policy makers in trajectories of change (Shove, 2010). However, these campaigns could also be interpreted as attempts to change the meanings, competencies and materials associated with this practice, and resurrect old 'traditional' practices that do not require the use of antibiotics (Maller and Strengers, 2013). We consider these possibilities below.

\section{Reframing antibiotics: A limited resource with socially shared implications}

Campaigners, health professionals and academics have long warned against the over-use of antibiotics but until recently the issue has received little policy attention. In a recent interview, the UK Chief Medical Officer, Sally Davies, described emerging antibiotic resistance as a 'catastrophic threat' and warned that unless the issue is addressed, 'we will find ourselves in 
a health system not dissimilar to the early 19th Century'. Her latest report called for change in the understanding and response to antibiotic resistance at the public, health service, and government levels (Davies, 2013), and recommended inclusion of the issue alongside terrorism on the National Risk Register. These types of statements, while commonly interpreted as a traditional $A B C$ message, focus attention on the social implications of antibiotic use and may contribute to shifting the meanings associated with the practice of treating minor ailments with antibiotics. More specifically, they reframe antibiotics from a limitless and appropriate material of practice to one that should be used in a considered manner to preserve the effectiveness of antibiotics and the health of the wider community into the future.

A key message emerging in attempts to reduce antibiotic resistance is the concept of 'prudent use'. Communication materials provided to doctors as part of European Antibiotic Awareness Day (see http://ecdc.europa.eu/en/EAAD) emphasise the global social implications of unwarranted antibiotic use: 'antibiotic resistance is an increasingly serious patient safety and public health problem in England, Europe and the world'. This message is followed by a range of evidence which responds to doctors' tendency to immediately satisfy their individual patients' 'demands' for antibiotics. This evidence highlights how doctors can successfully draw on other professional competences, such as communication and clinical assessment skills, to ensure patient satisfaction and a healthy outcome, without contributing to the public health problem associated with unwarranted antibiotic use.

Other European Antibiotic Awareness Day communication materials can be conceptualised as reframing antibiotics as a limited material with the potential to impact on the health of others. For example, a patient brochure from Ireland (see Figure 1) continues the theme of 'prudent use' and visually presents the unwarranted use of antibiotics as 'waste' in a rubbish bin. The brochure seeks to revalidate 'old-fashioned' competences that don't rely on 
antibiotics, stating that 'the best way to treat most colds, coughs or sore throats is to drink plenty of fluids and get some rest'. 
Figure 1 Ireland patient brochure for the European Antibiotic Awareness Day campaign

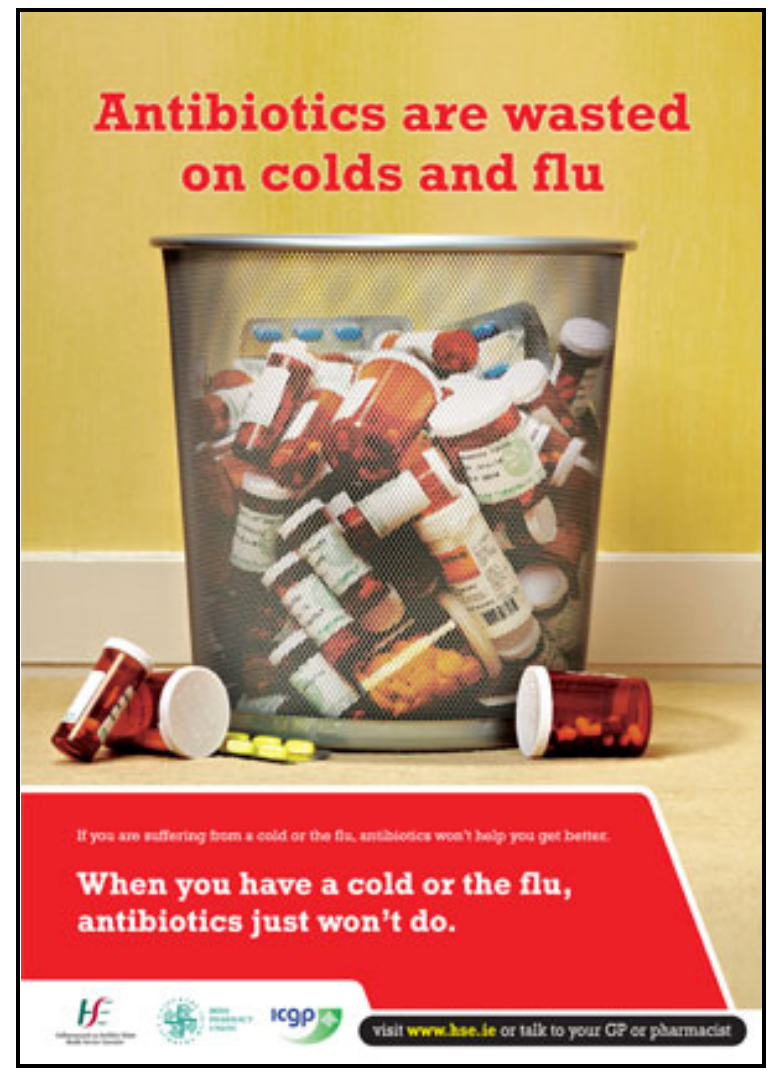

(C) European Center for Disease Prevention and

Control. Image from http://ecdc.europa.eu/en/EAAD 
Similarly, the National Prescribing Service (NPS) is a not-for-profit organisation, funded by the Australian Government, which runs programs to support 'good prescribing and decisions about medicines'. One NPS resource for doctors and patients promotes non-antibiotic alternatives to treating colds which were common in the past, such as resting or sucking on an ice cube (see Figure 2). From a practice theory perspective, this strategy can be interpreted as not only attempting to shift the meanings associated with antibiotics as a superior material for treating minor ailments, but also as seeking to resurrect 'old-fashioned' or 'inferior' competences and materials, by prioritising these less technologically-advanced approaches to treating a minor respiratory infection. The alternative ways to perform the practice promoted by the NPS resource are accessible and, coincidentally, some are similar to alternative competences associated with keeping cool without an air-conditioner on hot days (such as minimising physical activity and drinking icy beverages).

Maller and Strengers (Maller, 2011; Maller and Strengers, 2013; Strengers and Maller, 2012) have previously explored the benefits of resurrecting traditional practices in their study of Australian migrants. They found that some migrants resurrected domestic practices (heating, cooling, laundering and bathing) previously performed in their home countries, in response to droughts and other resource shortages experienced in Australia. Drawing on Shove and Pantzar (Shove and Pantzar, 2005), Maller and Strengers (2013) propose the concept of 'practice memory' to suggest that certain conditions or policy responses can be used to resurrect old ways of doing things from the past, bringing previously 'fossilised' practices back into circulation in similar or modified forms. Similarly, the policy responses discussed above could be considered attempts to resurrect fossilised practice memories of treating minor infections, albeit through conventional $A B C$ communication techniques. 
Figure 2 Part of a resource for doctors to prepare 'customised management plan' for patients with colds or influenza

YOUR CUSTOMISED MANAGEMENT PLAN
Patient name:
You have an infection of the ear, nose, throat, sinuses and/or chest. It is most likely
caused by one of the many common viruses that circulate in our community.
Antibiotics are not the best treatment for these infections. They won't treat the
symptoms or stop it from getting worse.
Rest, home remedies, decongestants and simple pain relievers can help you feel
better while your body's immune system fights off the infection.
What you can do to feel better
Tick $\downarrow$ where appropriate
$\square$ Rest
$\square$ Gargle warm salty water
$\square$ Suck on an ice cube or a throat lozenge
$\square$ Use salt water (saline) nasal drops or spray
$\square$ Inhale steam from the shower
$\square$ Drink something soothing (e.g. a honey and lemon drink)
$\square$ Apply moisturiser to soothe dry skin around the nose
$\square$ Use a decongestant nasal spray or drops
$\square$ Take a decongestant tablet or mixture
$\square$ Take paracetamol or ibuprofen (adults may take aspirin)
$\square$ Other

(c) National Prescribing Service trading as NPS MedicineWise.

Excerpt from upper respiratory tract infection symptomatic management pad resource. Reproduced with permission. 
It is important to reiterate that these examples do not address the antibiotic resistance problem in a coordinated practice theory-consistent manner-if indeed there is such a thing. There are many examples of conventional $A B C$ attempts to change patient behaviour as 'consumers' of antibiotics which focus predominantly on the personal benefits or disadvantages of antibiotic consumption. However, the above examples could be reconceptualised as attempts to shift the social meanings of antibiotics from an abundantlyavailable and liberally-used material to one which warrants prudent use to ensure its availability and effectiveness into the future. This strategy simultaneously involves introducing new configurations of meanings, competences and other materials into practices of treating minor respiratory infections. These new configurations potentially displace antibiotics from their current unnecessarily dominant role in achieving the aim of restoring health, and simultaneously seek to resurrect past practices as appropriate and effective to restore health.

This is not a new strategy: health campaigns regularly attempt to shift the social health meanings of practices, even though it is not explicitly defined in these terms. For example, campaigns to curb air pollution from poorly maintained vehicles or wood fires emphasise the health of the wider community rather than the individual involved. Similarly, 'environmental reasons' for reducing consumption of a resource such as energy emphasise implications beyond the individual. However, the future public health impacts of more energy-intensive practices (such as air-conditioned cooling) are rarely emphasised, and alternative ways of keeping cool are often downplayed or not discussed in demand management programs (Strengers and Maller, 2012).

With this in mind, we now turn our attention back to the problematic issue of air-conditioning use and summer peak demand to consider how demand management programs and policies might attempt to resurrect and circulate alternative cooling practices. 


\section{Studying household cooling practices}

Our analysis below is based on interviews conducted during 2012-13 with 80 households living in Sydney, Australia. Approximately half of the interviews involved multiple household members resulting in a total of 118 participants (62 females and 56 males). The ages of participants ranged from 25 years to 89 years of age, with fewer young participants (26 participants aged <45, 51 participants aged 45-64 and 41 participants aged $>64$ ). Participants were predominantly owner-occupiers of their homes with at least one member of the household doing paid work or, for older households, both members in retirement. Thirtyfive per cent of participants were born in a range of countries other than Australia.

Participants were recruited in two electricity distribution areas of Sydney via an invitation letter. All households were currently or previously part of a demand management program aimed at reducing their energy consumption during peak times. All interviews were conducted by one or both of the authors and ranged from 45 minutes to over two hours in length. Most interviews concluded with a tour of the home to discuss and demonstrate use of different energy appliances. Interview questions were semi-structured and sought to explore householder understandings and experiences of electricity use and supply, peak demand, demand management programs and the electricity industry. In addition, householders were questioned about the practices associated with energy consumption in the home and, where applicable, changes they had made in response to demand management programs. There was a particular focus on householders cooling practices. In the latter part of the interview, householders were read a prepared statement briefly explaining peak demand and associated implications for electricity supply, infrastructure needs and electricity pricing ii. Where necessary, further explanation was provided to assist householders in understanding peak demand but the topic of health was not part of the provided explanation of peak 
demand or its implications. Interviews were transcribed and thematically analysed using the qualitative data analysis software, NVivo.

In the discussion below we draw on our analysis of these individual interviews (Hitchings, 2012) to consider what socially shared meanings and competencies about electricity, peak demand and health are already in circulation in practices of keeping cool, and to speculate on the potential implications of discussing and communicating alternative meanings and competencies to encourage shifts and changes in practice.

\section{Meanings of electricity as an unlimited resource during peak times}

Most householders we interviewed did not understand peak demand and the implications for electricity supply in Australia such as increasing electricity prices and the risk of power outages, particularly on hot days. Despite being involved in demand management programs, householders generally considered that electricity providers could or should supply as much electricity as customers wanted. Arty's comments on this issue reflect a broader trend in the data, and resonate with Kurz et al.'s (2005) finding that electricity is widely viewed as technologically-produced and infinitely producible resource that should be available on demand.

Arty: 'I'm sure nowadays with the technology they've got, they've got plants now that they can increase their power and use less in the beginning, so I mean it's just a matter of using the technology now that they can produce more electricity at a certain peak and then they'll shut it down. I mean this should be, I mean you can't tell me that it's impossible...' 
Householders often directly linked these expectations of unlimited electricity generation and supply to an entitlement for 'creature comforts' and the 'continuous supply of airconditioners'. Ben's view was that people who 'work hard' should have access to airconditioning when they want it, for an affordable cost. From a practice perspective, electricity is framed here as an infinitely available material of air-conditioned cooling (Strengers and Maller, 2012), the entitlement to which reflects meanings about when, and by whom, airconditioning ought to be used. This is similar to the ways in which patients have come to expect (and in many cases demand) antibiotics to treat minor ailments without understanding the broader implications of this treatment (Butler et al., 1998; Wood et al., 2007).

Like Ben, most householders were not aware of peak demand and/or did not understand the implications of using air-conditioners on peak demand days, particularly its contribution to infrastructure costs and the increased risks of power outages. Many householders, particularly those who were on a 'time-of-use' demand management tariffiii, described peak demand as pricing-related daily time periods focused on breakfast and dinner times (early mornings and evenings).

Ron: '[Peak demand is] the time when the majority of people use electricity for everything, because you've got to put the lights on, you've got to cook meals, showers and all that sort of thing.'

The lack of understanding of peak demand, particularly in regards to the more infrequent critical peaks, and the meaning of electricity (specifically electrically-produced cooling) as abundant and available all the time is not surprising given that demand management programs are usually promoted as financial 'opportunities' for households. The causes and risks of peak demand are not the focus of the promotion or customer information provided as part of these demand management programs. 


\section{Counting the costs of air-conditioning}

The main 'reason' householders gave for changing their individual performance of the practice of keeping cool was to save money. Twenty households in our study were involved in a demand management program that offered rewards if householders reduced electricity consumption for a few hours during occasional peak demand days ('peak events' which the electricity nominated up to six times per year). This program encouraged householders to 'earn cash while you save energy', and attempted to make financial savings meaningful to household cooling practices during these times. However, householders that lacked interest in reducing their energy consumption during peak events often considered the cost of continuing to use their air-conditioning irrelevant in the context of keeping cool on a very hot day. For example, while Miles explained how it was difficult to manage financially as an elderly couple that relied on the pension for their income, the financial incentives offered to cut back during peak events were an insufficient reason for Miles and his wife to turn off the air-conditioning or find alternative ways of staying cool.

Miles: 'I decide whether I should turn [the air-conditioner] on or turn it off. I'm not worried about your, how much you charge me. If you charge me I'll just have to pay, and if I can afford to pay. And that's the best I could do...'

Similarly, Desi, a young single mother, had given up trying to respond to the peak demand program. She considered the level of financial reward insufficient for the effort she had made to avoid using the air-conditioner to perform the practice of keeping cool during a peak event.

Desi: 'It was... a really, really hot day we had, and I think I did turn, like not use the airconditioning but then it only reduced my bill by $\$ 1.40$ or something ridiculous and I 
thought it's just not worth it, it's not worth it. So I, the next time they [called a peak event] I just didn't even worry about it. [I] just used it as normal.'

Rather than viewing this as a problem of inadequate financial incentives, this response could be re-interpreted as an absence of meanings around the limited availability of electricity during peak times. The seemingly inconsequential energy savings households did, or could, achieve by participating in demand management programs, sometimes manifested in surprise or anger when householders were asked to reduce energy consumption on the hottest days of the year.

Gail: 'No, I didn't realise that it was going to be when [the weather was hot], I thought I'm just going to like, how would I say, pick a random [day], you know... My husband came home from work and [he] goes "It's crazy!"'

Lexie: 'Yes this summer it was quite a few [peak events]. But I started to laugh, I said to myself, we're having a heat wave at the moment, how could they do this to me? ...I ignore them [peak events]. It's not worth it.'

Similar to the ways in which Gail and Lexie expressed their frustrations and surprise above, the absence of understandings about the implications of over-use of antibiotics contributes to patient dissatisfaction which doctors encounter when they do not prescribe antibiotics as expected. Focusing on individual benefits, financial or otherwise, minimises the opportunity for the circulation of 'real reasons' (or less individually-focused meanings) into practices of staying healthy and cool. This focus also minimises opportunities to shift the practice entity more broadly through a widespread resurrection of less-resource intensive ways of keeping cool. 


\section{The health of others and home cooling}

The above discussion reveals how demand management programs that emphasise the costbenefits of reducing peak demand have a limited impact on shifting household cooling practices. Similar to the ways in which some health agencies emphasise the social health implications of unwarranted antibiotic use and attempt to resurrect alternative practices, we now consider the potential for demand management programs to emphasise the social health meanings of electricity in order to resurrect alternative ways householders can keep cool during peak times.

The householders we interviewed demonstrated that meanings of social health and wellbeing are already linked to the availability and costs of electricity. Most householders did not report difficulties paying their own electricity bill but many expressed their concerns for vulnerable people in the community who could not afford to use electricity, as Ben outlines below.

Ben: '[Lana] and I both work and we have a reasonable income here, so we can pay our bills and that's not an issue. But I do know people, elderly people that are not putting on electric blankets, and they're not cooking as much, and they're living in one room... and I think that's an indictment on the system when you allow the frail or the elderly or the low income not the opportunity to [afford electricity], it's an essential service; it's not something you can do without.'

In addition to widespread meanings of electricity as essential and unfairly unaffordable for some people that needed it, there were meanings of air-conditioned cooling as essential to maintain the health of some people in the community. For example, Mina did not consider 
using air-conditioning to be healthy or necessary for herself, but viewed air-conditioned cooling as important for particularly unwell and people and the elderly:

Mina: 'I understand that [air-conditioning] is necessary for nursing homes and if you've got someone sick in the house ... for example, the people next door are quite old. They can't cope with the heat...'

Regardless of concerns about electricity needs and the wellbeing of other, more disadvantaged or vulnerable people in the community, householders did not connect these meanings with the issues associated with air-conditioning usage during peak demand periods, including higher electricity prices and the potential risk of electricity outages. In discussions about their own cooling practices, householders that used air-conditioning focused on their own or their family's comfort needs and householders saw little reason not to rely on air-conditioned cooling if they could afford it. In other words, the meanings householders attached to their use of air-conditioned cooling were individualistic and expressed in terms of their personal convenience and comfort.

However, when peak demand was explained to householders during the course of the interviews, a curious phenomenon occurred. Householders connected home cooling on extremely hot peak demand days with its social health implications and this, in some cases, remarkably shifted meanings of entitlement and responsibility in relation to cooling practices. Specifically, interviewees were made aware that high demand for electricity at peak times can cause electricity shortages and contributes to price increases. While some householders did not accept this explanation due to a lack of trust in the electricity industry, other householders embraced this understanding of peak demand and proceeded to discuss its implications for the way they could, and perhaps should, cool their homes and bodies during these extreme periods of heat and high demand. Importantly, householders made the link 
between peak demand and their cooling practices on their own, prompting them to speculate on alternative methods of cooling their bodies and homes that they had learned and performed in the past.

For example, Don and Ella, an affluent older couple who had the highest electricity use in the sample, both agreed early on in the interview that there was nothing else they could do to save energy during the peak pricing period of their time-of-use electricity tariff. As the interview progressed and their understanding of peak demand and its implications for household cooling and social health improved, they became enthused about finding solutions to this problem. While not explicitly mentioning the health of others, Don likened critical peak demand days to the catastrophic Australian bushfire known as 'Black Friday' ('if I knew a Black Friday was coming up l'd be extra careful') and he identified the use of their ducted airconditioning as discretionary during those times. Don talked about how he and his wife 'used to manage without AC' noting that 'it wasn't fatal' and 'they survived'. Don's reference to Black Friday was consistent with other householders' responses to the explanation of peak demand. Householders reframed peak demand days as a potentially dangerous phenomenon with clear health implications (despite the absence of these ideas from the explanation of peak demand provided). Don and others suggested that, like with high bushfire risk days, households could be warned about approaching peak demand days. He thought that households would then be able to reduce their own electricity use to help maintain the electricity supply for people that really need household cooling and for hospitals.

A similar shift was observed over the course of the interview with Desi, who did not sustain her attempt to avoid using the air-conditioner to stay cool on hot days in response to financial incentives offered in her current demand management program (see Section 6 above). Once peak demand was explained by the researchers, Desi connected household use of air- 
conditioned cooling during peak times to her pre-existing understanding of electricity as being essential for the health of vulnerable people and prioritised their needs:

Desi: 'The younger people who really can handle the heat, [they should] not [be] using it so the old people who really can't handle the heat and need to run their air-conditioning [can use it]. I would do that for sure.'

During the course of the interview, Desi highlighted other competences associated with materials other than the air-conditioner that she could perform to stay cool on particularly hot summer days, such as avoiding vigorous exercise (not using her running treadmill), maximising the flow of the breeze through her home or taking her daughter to the pool. Similarly, most householders had practice memories of competences that they currently or had previously used to keep cool without using the air-conditioner (which they considered resurrecting during peak times). For example, Miles and his wife Sadi spent hot days in an open garage area which they had set up to enable them cook the evening meal without having to go inside. When asked what other things they did to stay cool, Miles described how they used water to cool down: '[we] have a bath, hosepipe. ...We play at times...We still feel young you know, sometimes.'

Similarly, Jane had many other practices for staying cool that she already performed as alternatives to air-conditioned cooling. Once she considered the potential social health meanings of air-conditioned cooling during peak times, she was more enthusiastic about performing these practices.

Jane: 'When it's really, really hot, I'll take the kids out. If it's too hot to swim, you know if it's one of those, and they only happen so rarely, if it's 40-something degrees and it doesn't matter how much air-conditioning you put on sometimes, it's just awful, that's 
when I'll take them to a shopping centre. Or a lot of the other places around, play centres and things like that, you know are alright. Or we'll sometimes go down to Oatley Park on the beach there and there's a big covered area, we'll take lots of ice blocks and you know just, as long as they're hydrated in the shade, and not running around too much, you know they're fine.'

Importantly, we are not interested in these quotes as individual views or intentions, even though they are clearly individually expressed. Rather these findings reflect a broader response across our sample; the connections between peak demand, health and household cooling practices were socially-shared. As householders expressed these shared meanings around the social health implications of peak demand, some discussed strategies for circulating these meanings more widely. They started to think of innovative strategies to encourage fellow householders to reduce peak consumption, including the promotion of 'health messages':

Jane: 'So it's more of a health message, rather than electricity use message. So it's more of a positive rather than "stop using electricity at this time", but you know, "look, during these times, it's going to be really hot, the demand's going to be really high, if everybody turns a thing on everybody's going to be without it". So let's suggest that, you know, "you do this, this, and this and plan ahead for those days".'

Andy also suggested a campaign that emphasises the health impacts of using airconditioning during peak times, making links to similar campaigns in the health sector:

Andy: 'Yeah, they could actually do simple advertisements. The one I'm thinking of is the the one they do about getting a tan at the moment. That really hits home, that a tan is not healthy and that it leads on to skin cancer stuff...' 
While we are unable to assess whether these shared connections between the health implications of peak demand and household cooling practices resulted or would result in an actual change in cooling practices, they clearly encouraged interviewees to reconsider their current methods of cooling in similar ways. Householders speculated about the suitability and appropriateness of less energy intensive, more 'old-fashioned' alternatives for keeping cool at peak demand times. In other words, they discussed potential changes in practice, drawing on their memories from the past.

It is important to note that governments and energy companies already promote many other less energy-intensive ways of keeping cool at home through advertising and communication materials. However, our analysis suggests that these alternative practices are not considered necessary or appropriate until existing air-conditioned cooling practices are disrupted by, as this study suggests, shifting meanings associated with electricity, health and air-conditioned cooling during peak times. Further, communicating these alternatives is not necessary for many households who already have memories of alternative ways to stay cool with airconditioning. This suggests that simply encouraging householders to perform practices from the past is unlikely to achieve the desired policy outcome of peak demand shifts. Rather, policy responses to this issue also need to focus attention on how to disrupt the dominant meanings, competencies and materials associated with home cooling, before resurrection of past practices can occur.

\section{Conclusion}

In this paper we have drawn on social practice theory to consider the implications of emphasising the social health implications of two practices that are typically framed around the 'needs' and comfort preferences of individuals. We have argued that discussing peak 
demand with households can reposition electricity as a social health issue which in turn can change the meanings associated with electricity and air-conditioned cooling on hot days. This represents an important potential opportunity for demand managers and energy policy makers seeking to reduce the impacts of peak electricity demand. In making these links, we have drawn inspiration from the example of healthcare campaigns that attempt to emphasise the social health implications of using antibiotics imprudently to treat minor respiratory infections.

Our research with Australian households suggests that meanings regarding the importance of preserving the health and the needs of vulnerable others are already in circulation, but are not currently connected with the practice of air-conditioned cooling to maintain comfort on very hot days. However, we found that when peak demand and its implications for electricity supply and electricity prices were understood, householders connected these meanings of health for the elderly and frail with the practice of air-conditioning on hot days. Householders' reconfiguration of air-conditioned cooling as a practice with socially-shared implications resulted in them drawing on their practice memories to consider a range of alternative cooling practices that they could participate in on very hot days. This change occurred despite many of the householders we interviewed indicating that the financial incentives they were receiving from demand management programs were insufficient to encourage a change in air-conditioned cooling practice at times of peak demand.

In making these claims, we acknowledge that neither our antibiotic example nor our fieldwork provides evidence of actual changed practice. Further, we encourage caution in proceeding with a strategy to promote the health implications of household cooling, as seeking to intervene in a practice can have unintended, and sometimes counter-productive results (Shove and Walker, 2010). Further research is needed to explore how social health 
meanings might disrupt air-conditioned cooling practices and other possible outcomes of this type of intervention.

Having said that, our analysis clearly suggests that demand management programs that only highlight the financial costs and benefits of air-conditioned cooling during peak times are inherently limited. In contrast, the 'costs' to the health of others resonate as 'real reasons' to reduce peak consumption, and may engage householders to participate in alternative practices to keep cool on very hot days. Similar practices are being encouraged to circulate in health campaigns that seek to shift the meanings associated with using antibiotics in order to preserve the supply of antibiotics as an essential resource for the future. We encourage the energy industry and energy policy makers to look towards innovative examples like this for insights into how social health meanings might be utilised to achieve demand management outcomes, and to think about this through the conceptual lens of social practices. The scale and scope of continuing antibiotic and air-conditioning use warrants further investigation of these and other possibilities.

Acknowledgements: The research presented in this paper was conducted as part of the Co-managing Home Energy Demand project funded by TransGrid and supported by Ausgrid and Endeavour Energy and the authors are grateful for their support and assistance. We also thank the research participants for their time and the reviewers for their feedback on this paper. This paper represents the views of the authors. 


\section{References}

Aaland, M., 1978. Sweat: The illustrated history of the Finnish sauna, Russian bania, Islamic hammam, Japanese mushi-buro, Mexican temescal and American sweat lodge. Capra Press, Santa Barbara, USA.

ABS, 2011. Environmental issues: Energy use and conservation. Australian Bureau of Statistics (ABS), Canberra, Australia.

AEMC, 2011. Final report - Possible future retail electricity price movements: 1 July 2011 to 30 June 2014. Australian Energy Market Commission (AEMC), Sydney, Australia.

ASHRAE, 2004. Standard 55: Thermal environment conditions for human occupancy. American Society of Heating Refrigeration and Air-Conditioning Engineers (ASHRAE), Atlanta, USA.

Auliciems, A., 1972. The atmospheric environment: A study of comfort and performance. University of Toronto Press, Toronto, Canada.

SGV (Better Health Channel), 2013. Fact sheet: Antibacterial cleaning products, State Government of Victoria (SGV), Australia. Available at:

http://www.betterhealth.vic.gov.au/bhcv2/bhcarticles.nsf/pages/Antibiotic_resistant_bacteria Bi, P., Williams, S., Loughnan, M., Lloyd, G., Hansen, A., Kjellstrom, T., Dear, K., Saniotis, A., 2011. The effects of extreme heat on human mortality and morbidity in Australia: Implications for public health. Asia-Pac. J. Public Health 23, S27-36.

Bonnefoy, X.R., Annesi-Maesano, I., Aznar, L.M., Braubach, M., Croxford, B., Davidson, M., Ezratty.V., Fredouille, J., Gonzalez-Gross, M., van Kamp, I., Maschke, C., Mesbah, M., Moissonnier, B., Monolbaev, K., Moore, R., Nico, S., Niemann, H., Nygren, C., Ormandy, D., Röbbe, N., Rudnai, P., 2004. Review of evidence on housing and health: Background document, 4th Ministerial Conference on Environment and Health, Budapest, Hungary. Butler, C.C., Maggs-Rapport, F., Pill, R., Rollnick, S., Stott, N., 1998. Understanding the culture of prescribing: Qualitative study of general practitioners' and patients' perceptions of antibiotics for sore throats. Br. Med. J. 317, 637-642. 
Cockburn, J., Pit, S., 1997. Prescribing behaviour in clinical practice: Patients' expectations and doctors' perceptions of patients' expectations - a questionnaire study. Br. Med. J. 315, $520-523$.

Davey, P.G., Bax, R.P., Newey, J., Reeves, D., Rutherford, D., Slack, R., Warren, R.E., Watt, B., Wilson, J., 1996. Growth in the use of antibiotics in the community in England and Scotland in 1980-93. Br. Med. J. 312, 613.

Davies, S.C., 2013. Infections and the rise of antimicrobial resistance. Annual report of the Chief Medical Officer, volume two, 2011. Department of Health, London, United Kingdom. DoH, 1999. The path of least resistance. Standing Medical Advisory Committee Sub-Group on Antimicrobial Resistance, Department of Health (DoH), London, United Kingdom.

DoTI, 2011. Energy Assistance Guide. Department of Trade and Investment (DoTI), Sydney, Australia.

ECDC/EMA, 2009. The bacterial challenge: Time to react - Joint technical report. . European Centre for Disease Prevention and Control (ECDC) and European Medicines Agency (EMA) Stockholm, Sweden.

ESAA, 2012. The real cost of air-conditioners. Energy Supply Association of Australia (ESAA). Available from: www.esaa.com.au/policy/the_real_cost_of_air_conditioners_1 Evans, D., McMeekin, A., Southerton, D., 2012. Sustainable consumption, behaviour change policies and theories of practice. Collegium: Studies across disciplines in the humanities and social sciences $12,113-129$.

Farbotko, C., Waitt, G., 2011. Residential air-conditioning and climate change: Voices of the vulnerable. Health Promot. J. Austr. 22, S13-S16.

Faruqui, A., Palmer, J., 2011. Dynamic pricing and its discontents: Empirical data show dynamic pricing of electricity would benefit consumers, including the poor. Regulation 34, 1622.

Gram-Hanssen, K., 2007. Teenage consumption of cleanliness: How to make it sustainable? Sustainability : Science, Practice and Policy 3, 15-23. 
Hargreaves, T., 2011. Practice-ing behaviour change: Applying social practice theory to proenvironmental behaviour change. Journal of Consumer Culture 11, 79-99.

Hitchings, R., 2012. People can talk about their practices. Area 44, 61-67.

Klinenberg, E., 2002. Heat wave : A social autopsy of disaster in Chicago. University of Chicago Press, Chicago.

Kurz, T., Donaghue, N., Walker, I., 2005. Utilizing a social-ecological framework to promote water and energy conservation: A field experiment. J. Appl. Soc. Psych. 35, 1281-1300.

Mainous, A.G., Evans, M.E., Hueston, W.J., Titlow, W.B., McCown, L.J., 1998. Patterns of antibiotic-resistant Streptococcus pneumoniae in children in a day-care setting. J. Fam. Practice 46, 142-146.

Maller, C., 2011. Practices involving energy and water consumption in migrant households, in P Newton (ed.), Urban Consumption, CSIRO Publishing, Collingwood, 237-250.

Maller, C., Strengers, Y., 2013. The global migration of everyday life: Investigating the practice memories of Australian migrants. Geoforum 44, 243-252.

Mangione-Smith, R., Elliott, M.N., Stivers, T., McDonald, L., Heritage, J., McGlynn, E.A., 2004. Racial/ethnic variation in parent expectations for antibiotics: Implications for public health campaigns. Pediatrics 113, e385-e394.

Morris, C.J.G., Simmonds, I., 2000. Associations between varying magnitudes of the urban heat island and the synoptic climatology in Melbourne, Australia. Int. J. Climatol. 20, 19311954.

Schatzki, T., 1996. Social practices: A Wittgensteinian approach to human activity and the social. Cambridge University Press, Cambridge.

Schatzki, T., 2002. The site of the social: A philosophical account of the constitution of social life and change, The Pennsylvania State University Press, Pennsylvania.

Sheridan, S.C., 2007. A survey of public perception and response to heat warnings across four North American cities: An evaluation of municipal effectiveness. Int. J. Biometeorol. 52, 3-15. 
Shove, E., 2003. Comfort, cleanliness and convenience : The social organization of normality. BERG Publishers, New York.

Shove, E., 2010. Beyond the ABC: Climate change policy and theories of social change, Environment and Planning A 42, 1273-1285.

Shove, E., Pantzar, M., 2005. Fossilisation. Ethnologia Europaea 35, 59-63.

Shove, E., Pantzar, M., Watson, M., 2012. The dynamics of social practice: Everyday life and how it changes. SAGE Publications, London.

Shove, E., Walker, G., 2010. Governing transitions in the sustainability of everyday life. Res. Policy 39, 471-476.

Spellberg, B., Guidos, R., Gilbert, D., Bradley, J., Boucher, H.W., Scheld, W.M., Bartlett, J.G., Edwards, J., 2008. The epidemic of antibiotic-resistant infections: A call to action for the medical community from the Infectious Diseases Society of America. Clin. Infect. Dis. 46, $155-164$

Stott, N.C., 1979. Management and outcome of winter upper respiratory tract infections in children aged 0-9 years. Br. Med. J. 1, 29-31.

Strengers, Y., 2012. Peak electricity demand and social practice theories: Reframing the role of change agents in the energy sector. Energy Policy 44, 226-234.

Strengers, Y., 2013. Smart energy technologies in everyday life: Smart utopia?, Consumption and Public Life Series. Palgrave MacMillan, London.

Strengers, Y., Maller, C., 2011. Integrating health, housing and energy policies: Social practices of cooling. Build. Res. Inf. 39, 154-168.

Strengers, Y., Maller, C., 2012. Materialising energy and water resources in everyday practices: Insights for securing supply systems. Global Environ. Chang. 22, 754-763. Trippett, F., 1979. Time essay: The great American cooling machine. Time 114, 75. Warde, A., 2005. Consumption and theories of practice. Journal of Consumer Culture 5, 131153.

Whitfield, M.J., Hughes, A.O., 1981. Penicillin in sore throat. The Practitioner 225, 234-239. 
Wood, F., Simpson, S., Butler, C.C., 2007. Socially responsible antibiotic choices in primary care: A qualitative study of GPs' decisions to prescribe broad-spectrum and fluroquinolone antibiotics. Fam. Pract. 24, 427-434.

WHO, 2009. Improving public health responses to extreme weather/heat-waves EuroHEAT. World Health Organisation (WHO) Europe, Copenhagen.

\section{Footnotes:}

'Peak demand explanation: In the late afternoon and early evening there are a lot of household activities (e.g. lighting, air-conditioning or heating, TV and computer use, cooking, showering, washing clothes) happening in households. This leads to the spike in energy usage called peak demand. The energy providers have to maintain enough infrastructure to supply households during peak demand times and to avoid power outages (blackouts). The peak demand spikes are extra big on very hot and very cold days. This means that a lot of extra electricity infrastructure is needed to supply enough electricity on these few days of the year. This infrastructure is expensive and is not used for about $98 \%$ of the year, but the need for it is a major contributor to recent increases in electricity costs.

iinterviewee pseudonyms are used

\footnotetext{
iiiTariff with a higher rate for electricity used in the afternoon and early evening and lower rates for electricity used in the morning and overnight.
} 